CONTROL OF EMISSIONS FROM OIL FIRED PLANTS - M.A. BERRY.

\title{
INTRODUCTION
}

Liquid petroleum fuels available on the South African market for firing industrial plants are LPG, kerosine, gas oil and heavy furnace oil. Typical characteristics of these fuels are:-

Density $\propto 20^{\circ} \mathrm{C}$

Viscosity $\operatorname{cs} . \alpha 37,8^{\circ} \mathrm{C}$

Sulphur \% mass max.

typical

Gross calorific value Btu/lb.

$\mathrm{MJ} / \mathrm{l}$.
L.P.G. Kerosine

0,55

0,2

0,018

0,010

21,450

27,440
0,80

1,2

0,25

0,18

19,900

46,285
Gas Oil H.F.F.

$$
0,83 \quad 0,95
$$

2,6 $250(\max$.

$0,5 \quad 3,5$

0,3

3,0

19,700

18,700

$45,820 \quad 41,105$

\section{EMISSIONS FROM OIL FIRED PLANTS}

The emissions from plants fired by these fuels which have to be considered from the air pollution aspect and either discounted as innocuous or accepted as potential nuisances and measures developed to eliminate the nuisance are:-
a) Carbon dioxide
b) Carbon monoxide
c) Water vapour
d) Soot and unburnt hydrocarbons
e) Emissions from process materials
f) Sulphur dioxide
g) Sulphur trioxide and acid smuts
h) Nitrogen oxides

\section{CARBON DIOXIDE}

All fossil fuels contain carbon. The product obtained by complete combustion of this carbon is carbon dioxide. Both from the standpoint of air pollution and from considerations of fuel economy it is essential 
to burn all the carbon to carbon dioxide, otherwise the full heating potential of the fuel is not developed i.e. the plant operates at a low efficiency.

Some concern has been expressed that burning fossil fuels on an ever increasing scale will result in an increase in the carbon dioxide content of the atmosphere and this might have an effect on the world heat balance. It is difficult to express any opinion on this matter, since so little factual data is available on the scale of the problem or if indeed there is one. Some recent figures which have been quoted are that the concentration of carbon dioxide is increasing by $1.3 \mathrm{ppm}$. per year and the level in 1972 was $324 \mathrm{ppm}$. The lack of information on the fate of carbon dioxide does not however seem to restrain comment so it is tempting to throw a further red herring into the discussion by pointing out that enrichment of the air in greenhouses by carbon dioxide which is a well established technique in many parts of Europe, has been shown to promote quicker and greater growth of vegetation and fruits an obviously desirable result.

\section{CARBON MONOXIDE}

Carbon monoxide is not an important pollutant from industrial oil fired plants although much attention is now being given to low level emissions from internal combustion engines. In industries such as the iron and steel industry where large amounts of carbon monoxide are necessarily produced and handled in the process, great care is taken to confine the product not only from the pollution aspect but also from the safety standpoint. If oil fired equipment is so badly maintained and adjusted as to produce large amounts of carbon monoxide, then copious amounts of smoke, soot and unburnt hydrocarbons will be concurrently produced. There is no excuse for such a situation since adequate maintainance and proper adjustment of equipment will solve this problem without recourse to special techniques.

Since one pound of carbon burnt to carbon dioxide liberates just over $14000 \mathrm{Btu}$ whereas when only partially burnt to $\mathrm{CO}$, the heat liberation 
is $3960 \mathrm{Btu}$ or $28 \%$ of the potential, any industrialist who permits such a situation to develop is throwing money away as well as annoying the Air Pollution authorities.

\section{WATER VAPOUR}

Because petroleum fuels contain hydrogen, water vapour is produced when they are burnt. Water vapour as a pollutant can be discounted in view of the immense amounts occuring naturally in the atmosphere. It is not unusual however for photographs of stacks emitting large amounts of what appears to be fume to be published as horrible examples of pollution. Close inspection of such photographs often indicates that the "pollutant" is really innocuous steam.

\section{SOOT AND UNBURNT HYDROCARBONS}

There is no problem in burning LPG and the two distillate fuels with complete cleanliness and freedom from soot and unburnt hydrocarbons. When burning heavy furnace fuel, a good well maintained modern burner can operate continuously with a "stack solids" content in the flue gases of less than $0.2 \%$ by mass of fuel burnt. "Stack solids" means fine soot, ash from the oil and solid unburnt hydrocarbons. Combustion efficiency is therefore better than $99.8 \%$ complete. These stack solids are extremely finely dispersed and are liberated from the stack completely invisibly and without nuisance except when acid smut formation (described below) occurs.

\section{PROCESS EMISSIONS}

Emissions from materials being processed although extremely important from air pollution considerations are inherent to the process whatever fuel is being used and not relevant to the subject of this paper.

\section{$\underline{\text { SULPHUR DIOXIDE }}$}

Liquid petroleum fuels, similarly to solid fuels contain sulphur to a lesser or greater extent. Inspection of the typical sulphur contents of industrial fuels above indicates that the content only becomes signi- 
ficant in the HFF grade. It should, however, be recognised that because of the higher calorific value of oil and the greater efficiency of oil fired equipment a $3 \%$ sulphur oil is approximately equivalent to a $1.5 \%$ sulphur coal.

When oil is burnt, the sulphur is converted to sulphur dioxide. There are two schools of thought about how the emission of sulphur dioxide should be handled. The first school represented by the Americans and Continental countries insists that the absolute amount of sulphur dioxide emitted to the atmosphere should be limited. Such restrictions were met in the first place by using fuel oils derived from crude oils naturally low in sulphur. Such crudes however, are in limited supply and the preemptive demands for low sulphur fuels for ordinary burning purposes from these countries absorbed supplies of low sulphur oil which would have been better utilised in industries such as the steel industry where low sulphur fuels are technically desirable. In the event, demands for low sulphur fuels have now reached such a level that they cannot be met and in many countries the restrictions on sulphur dioxide emission have had to be relaxed to permit burning higher sulphur oils. If low sulphur fuel oil is not available and this approach prevails, the next logical step is to require removal of sulphur from fuel oil or removal of sulphur dioxide from flue gases. The latter, by the way, is the only option available to coal. The costs of these operations is staggeringly high. For example, a plant to desulphurise 1 million tons/year Kuwait oil to $1 \%$ sulphur will cost about R15 000000 and add at least R5,7 / ton or 0,57 cents / litre to the price of oil. A flue gas desulphurisation plant to remove sulphur dioxide resulting from burning 1 million tons will cost about $R 18000000$ and add R5,8 per ton of oil burnt to the operating costs.

The second school, represented by the U.K. takes the view that it is not the absolute amount of sulphur dioxide emitted which is important since natural means exist to remove this from the atmosphere but the ground level concentration where humans and plants live and breathe. This leads to what is called the "tall stack" policy. Stack heights, gas 
efflux velocities and exit temperatures are set at such levels that the plume of effluent gases is dispersed harmlessly into the upper atmosphere without causing localised high sulphur dioxide concentrations. The success of this policy has been very marked in the U.K. where ground level concentrations are steadily dropping despite the increasing tonnage of high sulphur oil being burnt. The tall stack is not effective when atmospheric inversion occurs as this prevents the flue gas plume dispersing in the upper atmosphere but this can be overcome by changing to a low sulphur oil whilst infrequent conditions prevail.

\section{SULPHUR TRIOXIDE}

Of the sulphur dioxide produced by burning oil a small proportion up to say $3 \%$ is oxidised further to sulphur trioxide, the anhydride of sulphuric acid.

When surfaces i.e. ducts, fan impellers and casings, chimneys in contact with flue gases are operating at temperatures below the acid dew point, sulphuric acid condenses on these surfaces. If the material of the surface is not resistant to attack, corrosion occurs. This corrosion as such is of no significance to air pollution authorities even though it is a financial burden to the industrialist but if smut emission is concurrently experienced and this is very likely, it becomes a prime item of concern.

\section{$\underline{\text { ACID SMUTS }}$}

Smuts are produced when fine carbon which would otherwise be discharged innocuously and unnoticeably from stacks, adheres to the wet acid film and agglomerates. Changes of load, wind direction, gas velocity can result in agglomerates becoming detached from the surface and carried out of the chimney to fall in the neighbourhood.

\section{ELIMINATION OF SMUTS}

Smut emission is associated with three factors:- presence of unburnt solids, presence of sulphur trioxide in the flue gases and relatively low 
temperatures of surfaces in contact with these gases. Much research effort has been devoted to indentifying the factors responsible and to the development of methods for eliminating the problem.

The first approach is to ensure that combustion is as near complete as possible so that the quantity of solids carried out in the gases is reduced to the minimum. This can be achieved by the installation of good quality equipment, properly adjusted and maintained.

The second step is to prevent the formation of sulphur trioxide or if this cannot be prevented, to prevent acid deposition. Three methods have been found satisfactory.

a) Combustion Control:- Oxidation of $\mathrm{SO}_{2}$ and $\mathrm{SO}_{3}$ is virtually eliminated when oil is burnt at low excess air levels. European power stations habitually operate with excess oxygen less than $1 \%$. Smokeless operation at these low excess air levels can be achieved at the low combustion intensities common in power station boilers. Competition in the packaged boiler field is tending to increase combustion intensity in this type of plant and not all burners fitted to these boilers can operate with both low stack solid production and low excess air.

b) Maintenance of surface temperatures:- If the temperature of surfaces in contact with flue gases is maintained above the acid dewpoint, acid cannot condense. This is achieved by stopping the influx of cold air into the flue gases, reducing the heat loss from surfaces by insulation or by increasing the temperature of water entering the economiser.

c) Neutralisation:- Sulphur trioxide can be neutralised by basic compounds such as ammonia, dolomite or magnesium oxides. Ammonia addition is the simplest but is best applied to plant operating under steady load conditions. 
Chimneys present a special problem. With unlined steel chimneys, the rate of heat loss is high and provision must be made to ensure the maintenance of adequate internal skin temperatures. In coastal regions of S.A. it will probably be satisfactory to fit cladding. In this method the steel chimney is sheathed with aluminium leaving an air gap between the aluminium sheathing and the chimney. On the Reef and in other areas where low temperature winter conditions are experienced, full chimney insulation will be called for. If a brick chimney already exists, an internal flue or flues can be inserted in the brick chimney, the gap between flue and chimney being filled with loose insulation.

When gases are emitted from chimneys at low velocity, "downwash" can occur, waste gases being drawn down the lee side of the chimney. A low gas velocity also allows cold air to enter the chimney and cool the upflowing gases and chimney wall. ("Inversion"). Plume rise is reduced and smut formation can occur.

To eliminate downwash and inversion, efflux velocities should be 1,5 times the average wind speed. Modern chimney design allows for an efflux velocity of about $12 \mathrm{~m} / \mathrm{s}(40 \mathrm{f} / \mathrm{s})$ at full load. If this velocity cannot be obtained by natural draught, fans will be required.

\section{NITROGEN OXIDES}

In the high temperature zones of a furnace or boiler fired with either liquid or solid fossil fuels, nitrogen and oxygen combine to produce nitrogen oxides. These compounds can react with unburnt hydrocarbons in the presence of sunlight to produce acrid smelling and irritating materials. Various methods of minimising the production of nitrogen oxides which show promise are being investigated e.g. recirculation of flue gases, two stage combustion, low excess air combustion and it may be necessary to incorporate the necessary equipment in some particular instances. In general, however, the tall stack policy referred to earlier, which has been successful in controlling ground level concentrations of 
sulphur dioxide will also satisfactorily control the ground level concentration of nitrogen oxides.

\section{CONCLUSION}

Methods have been developed to eliminate any nuisance caused by the emissions from oil fired plants. Since the means are available, control of emissions is now a matter of wholehearted acceptance of the philosophy that control is desirable.

\section{ACKNOWLEDGEMENT}

Permission to present this paper has been given by BP Southern Africa (Pty) Ltd. 